\title{
The Effect of Different Pruning Types on the Growth and Yield Capacity of Plum Varieties Fortune and Vengerka Domestica in Conditions of Armavir Community in Armavir Region
}

\author{
E.R. Stepanyan, A.L. Yepremyan, S.S. Simonyan \\ Armenian National Agrarian University \\ eteri_stepanyan@mail.ru, epremyan98@mail.ru, susanna.simonyan.1997@mail.ru
}

\section{A RT I CLE I N F O}

Keywords:

pruning,

trimming,

fruit,

yield,

variety

\begin{abstract}
A B S T RA C T
Pruning is vital for producing healthy and high quality yield. Nowadays, pruning of fruit and berry plants is considered to be one of the most important agro-technical measures. The role of pruning and trimming is significant in the improvement of sanitary conditions in orchards, as well as in foliage development, pest control, regular tree growth, fruiting regulation and its periodicity reduction.

In the result of our investigations it is recommended that annual medium/moderate pruning should be implemented in the orchards of Fortune plum variety and for Vngerka domestica plum variety light or moderate pruning should be implemented.
\end{abstract}

\section{Introduction}

Plum is one of the most widespread fruit species among the drupaceous fruits. It has been cultivated for more than 3000 years. In Armenia, it is the 3rd drupaceous fruit type by its significance and in case of precise varietal selection it can be cultivated in all regions. Anyhow, its industrial cultivation is centralized in piedmont zones, Ararat valley, North-Eastern regions and in the lowlands of Syunik region (Stepanyan, 2006). When establishing new orchards, it is essential to produce high-value fruit varieties by applying new technologies (Cherepakhin, 1983). Considering the plum tree as a high-value fruit bearing plant we have tried to disclose the effect of different types of pruning on the leaf mass variations, growth stimulation and yield capacity increase in the plum varieties of Vengerka domestica and Fortune.

Tree pruning is a prior measure among the activities of orchard cultivation. It is a way to direct your tree foliage into a specific shape as it grows, using selective cutting/ pruning techniques and limb positioning to achieve the desired end result upon the guidance of gaining maximum economic profit considering the peculiarities of the tree growth. Pruning activities are implemented in the orchards annually, starting from the planting year. Pruning methods can be drastically different related to the crop species, root stock strength, i.e., vigorousness, growing capacity and its peculiarities (Stepanyan, 2013). In the result of pruning 
it becomes possible to increase the buds excitability for maximum yield production (Margaryan and Shahinyan, 1976).

The research results are considered as a novelty in the Armenian horticultural branch, since almost no investigations for the Fortune plum variety have been ever conducted, while the recommended pruning type for Vengerka variety enables to ensure maximum yield capacity.

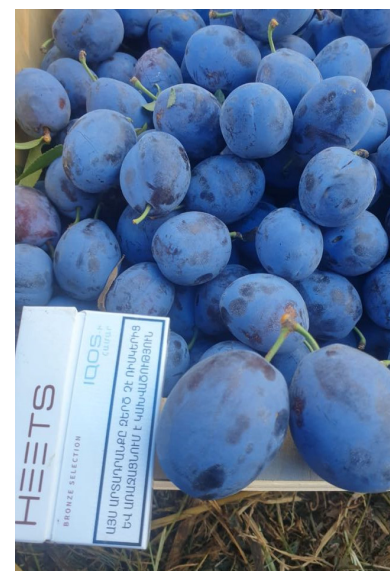

a. Fortune

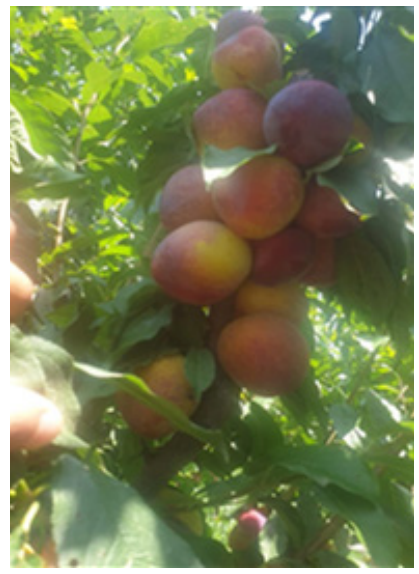

b. Vengerka domestica
Figure 1. Fruits of plum varieties of Vengerka domestica and Fortune

\section{Materials and methods}

The imported plum varieties Vengerka domestica and Fortune, grown in Armenia, have served as study objects (Figure 1). Cultivation of the mentioned varieties was organized in conditions of the Armavir community. The seed plants of cherry plum (Prunus cerasifera) and the seed plants of apricot tree (Armenica vulgaris) have served as rootstocks for the varieties Vengerka domestica and
Fortune respectively. The field experiments were carried out within the period of 2019-2020. The experiments were set up in 3 replications with 10 trees per each repetition. All varieties were planted upon 4x4 m feeding area with $4 \mathrm{~m}$ inter-row and $4 \mathrm{~m}$ interplant distances. The feeding area per a tree was $16 \mathrm{~m}^{2}$ and there were 625 trees per hectare. The experimented trees were 10-11 years old. All the activities implemented during the experiment were aimed at the solution of the following issues: identification of the effect of different pruning types on the leaf area variation of Vengerka domestica and Fortune plum varieties, that is on the growth stimulation of the mentioned varieties and last but not least on the increase of their yield capacity.

\section{Results and discussions}

The effect of pruning intensity on the plum varieties Vengerka domestica and Fortune is introduced in Table 1. In case of light pruning the leaf area of a plum tree variety Vengerka domestica in 2019 and 2020 years made $9.20 \mathrm{~m}^{2}$ and $9.54 \mathrm{~m}^{2}$ respectively. In the plum tree variety Fortune lower indices of leaf area for the same years were recorded making $8.20 \mathrm{~m}^{2}$ and $8.44 \mathrm{~m}^{2}$ respectively. When implementing moderate pruning the leaf area of a plum tree variety Vengerka domestica made $9.03 \mathrm{~m}^{2}$ and $9.48 \mathrm{~m}^{2}$ and in Fortune variety $-8.11 \mathrm{~m}^{2}$ and $8.14 \mathrm{~m}^{2}$ in the mentioned years. In case of severe pruning the same indices for the same years in the plum variety Vengerka domestica made $8.85 \mathrm{~m}^{2}$ and $8.94 \mathrm{~m}^{2}$ respectively, and in the Fortune variety they were accordingly $7.68 \mathrm{~m}^{2}$ and $7.89 \mathrm{~m}^{2}$. Thus, in case of applying various pruning types, the average leaf mass of the trees in the plum variety Vengerka domestica exceeded the same index of the Fortune plum variety.

When applying pruning of moderate intensity in both studied varieties biological and morphological properties characteristic to the plum tree were registered per the respective leaf areas of $9.25 \mathrm{~m}^{2}$ and $8.12 \mathrm{~m}^{2}$ as introduced in Table 1.

Table 1. The effect of pruning intensity on the leaf area of plum tree varieties of Vengerka domestica and Fortune*

\begin{tabular}{|c|c|c|c|c|c|c|}
\hline \multirow{3}{*}{ Variants } & \multirow{2}{*}{\multicolumn{3}{|c|}{$\begin{array}{l}\text { Vengerka domestica } \\
\text { The leaf area of a tree }\left(\mathrm{m}^{2}\right)\end{array}$}} & \multicolumn{3}{|c|}{ Fortune } \\
\hline & & & & \multicolumn{3}{|c|}{ The leaf area of a tree $\left(\mathrm{m}^{2}\right)$} \\
\hline & 2019 & 2020 & Average for 2019-2020 & 2019 & 2020 & Average for 2019-2020 \\
\hline Light pruning & 9.20 & 9.54 & 9.37 & 8.20 & 8.44 & 8.32 \\
\hline Moderate pruning & 9.03 & 9.48 & 9.25 & 8.11 & 8.14 & 8.12 \\
\hline Heavy/severe pruning & 8.85 & 8.94 & 8.89 & 7.68 & 7.89 & 7.78 \\
\hline
\end{tabular}

*Composed by the authors. 
Table 2. The effect of pruning intensity on the growth of plum tree varieties of Vengerka domestica and Fortune*

\begin{tabular}{|c|c|c|c|c|c|c|}
\hline \multirow{3}{*}{ Variants } & \multicolumn{3}{|c|}{ Vengerka domestica } & \multicolumn{3}{|c|}{ Fortune } \\
\hline & \multicolumn{2}{|c|}{$\begin{array}{c}\text { The number of shoots per } \\
\text { tree (n) }\end{array}$} & \multirow{2}{*}{$\begin{array}{l}\text { The average } \\
\text { number of shoots } \\
\text { (n) }\end{array}$} & \multicolumn{2}{|c|}{$\begin{array}{c}\text { The number of shoots per } \\
\text { tree (n) }\end{array}$} & \multirow{2}{*}{$\begin{array}{l}\text { The average } \\
\text { number of shoots } \\
\text { (n) }\end{array}$} \\
\hline & 2019 & 2020 & & 2019 & 2020 & \\
\hline Light pruning & 76 & 79 & 77 & 60 & 68 & 64 \\
\hline Moderate pruning & 47 & 58 & 52 & 37 & 39 & 38 \\
\hline Heavy/severe pruning & 26 & 28 & 27 & 32 & 42 & 37 \\
\hline
\end{tabular}

Table 3. The effect of pruning intensity on the yield capacity of plum tree varieties of Vengerka domestica and Fortune*

\begin{tabular}{|c|c|c|c|c|c|c|c|c|}
\hline \multirow[b]{3}{*}{ Variants } & \multicolumn{4}{|c|}{ Vengerka domestica } & \multicolumn{4}{|c|}{ Fortune } \\
\hline & 2019 & 2020 & \multirow[b]{2}{*}{$\begin{array}{c}\text { The average } \\
\text { yield } \\
\text { capacity } \\
\text { of tree for } \\
2019-2020 \\
\text { (kg) }\end{array}$} & \multirow[b]{2}{*}{$\begin{array}{l}\text { The average } \\
\text { weight of } \\
\text { fruits, } \\
\text { 2019-2020 } \\
\text { (g) }\end{array}$} & \multirow[b]{2}{*}{$\begin{array}{c}2019 \\
\text { The } \\
\text { average } \\
\text { yield of } \\
\text { tree } \\
(\mathrm{kg})\end{array}$} & \multirow[b]{2}{*}{$\begin{array}{c}2020 \\
\text { The } \\
\text { average } \\
\text { yield of } \\
\text { tree } \\
\text { (kg) }\end{array}$} & \multirow[b]{2}{*}{$\begin{array}{c}\text { The average } \\
\text { yield } \\
\text { capacity } \\
\text { of tree for } \\
2019-2020 \\
\text { (kg) }\end{array}$} & \multirow[b]{2}{*}{$\begin{array}{l}\text { The average } \\
\text { weight of } \\
\text { fruits, } \\
\text { 2019-2020 } \\
\text { (g) }\end{array}$} \\
\hline & $\begin{array}{c}\text { The } \\
\text { average } \\
\text { yield of tree } \\
\text { (kg) }\end{array}$ & $\begin{array}{c}\text { The } \\
\text { average } \\
\text { yield of tree } \\
\text { (kg) }\end{array}$ & & & & & & \\
\hline Light pruning & 104 & 100 & 102 & 76 & 32 & 38 & 35 & 62 \\
\hline Moderate pruning & 43 & 56 & 49 & 110 & 17 & 21 & 19 & 68 \\
\hline $\begin{array}{l}\text { Heavy/severe } \\
\text { pruning }\end{array}$ & 27 & 28 & 28 & 110 & 8 & 9 & 9 & 74 \\
\hline
\end{tabular}

In the result of light pruning in both varieties - Vengerka domestica and Fortune - the highest indices for the average leaf area in the plum trees were recorded. While in case of heavy (severe) pruning the average leaf areas in the trees recorded the lowest values.

The effect of pruning of different intensities on the growth of the plum tree varieties Vengerka domestica and Fortune is summarized in Table 2.

In 2019-2020, as a result of light pruning implemented in the Vengerka domestica plum variety, the number of shoots developed per tree made 76 and 79 respectively. In the plum tree variety of Fortune, the number of newly developed shoots was 60 and 68 respectively.

Within the same period when implementing moderate pruning in the plum variety of Vengerka domestica, 47 and 58 shoots per tree were respectively developed, while in the plum variety of Fortune, the number of shoots made 37 and 39 in the respective years.

In case of heavy/severe pruning the number of newly developed shoots in the plum variety of Vengerka domestica made 26 and 28, while in the variety of Fortune it was 32 and 42 respectively.
In case of implementing pruning of light and moderate intensity the index of the average shoot number in both varieties exceeded the same index recorded in case of heavy/severe pruning. Particularly, in case of light and moderate pruning, the average number of shoots in the plum tree variety of Vengerka domestica made 77 and 52 respectively, while in case of severe pruning the same index was recorded as 27 . For the plum tree variety of Fortune in case of respective pruning types 64 and 38 shoots, while in case of heavy pruning 37 shoots were registered.

The effect of pruning intensity on the yield capacity of plum varieties of Vengerka domestica and Fortune is summarized in Table 3. In case of light pruning implemented in 2019 and 2020, the yield capacity per tree in the plum variety of Vengerka domestica made $104 \mathrm{~kg}$ and $100 \mathrm{~kg}$ respectively. In the same years the plum variety Fortune recorded lower yield capacity, which made $32 \mathrm{~kg}$ and $38 \mathrm{~kg}$ per tree. When implementing moderate pruning, the yield capacity of the plum variety Vengerka domestica amounted to $43 \mathrm{~kg}$ and $56 \mathrm{~kg}$ during the study years, while in the Fortune variety it made $17 \mathrm{~kg}$ and $21 \mathrm{~kg}$ respectively. In case of heavy pruning the mentioned indicator in Vengerka variety made $27 \mathrm{~kg}$ and $28 \mathrm{~kg}$, while in the Fortune variety it was $8 \mathrm{~kg}$ 

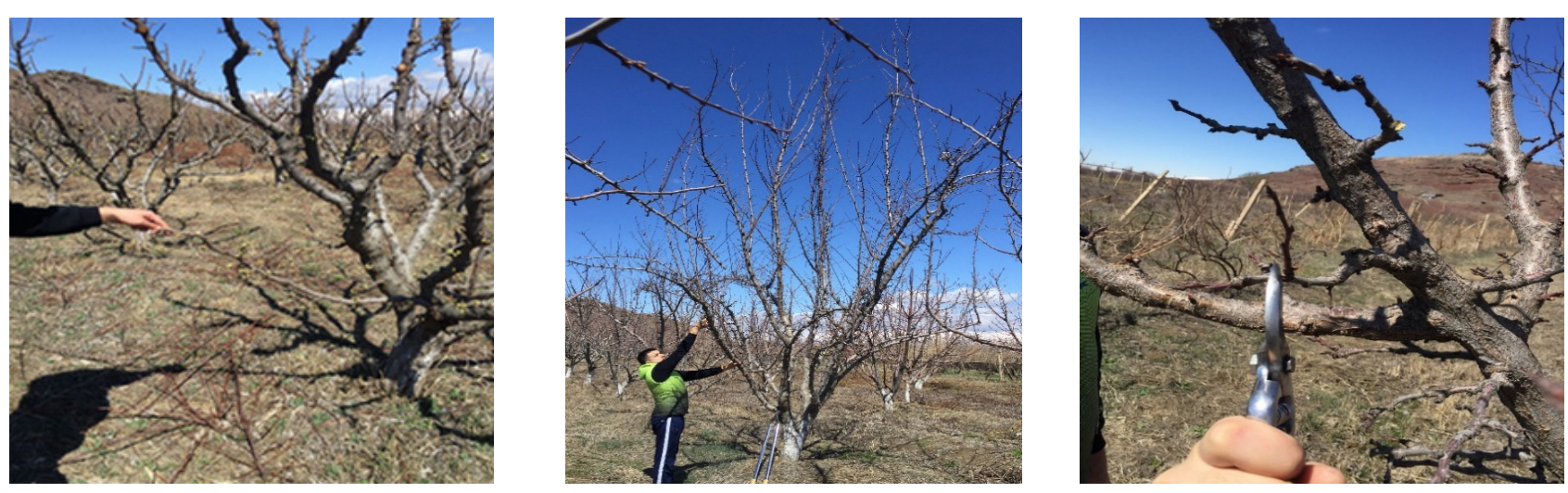

Figure 2. Pruning of the plum tree varieties Vengerka domestica and Fortune.

and $9 \mathrm{~kg}$ respectively. Thus, in both plum tree varieties high yield capacity indices were recorded in case of light pruning. In the plum variety of Vengerka domestica, the average yield capacity for 2 years was estimated as $102 \mathrm{~kg}$, while in the variety of Fortune the two-year average yield capacity was accounted as $35 \mathrm{~kg}$. Nevertheless, when implementing light pruning, in both studied varieties small fruit size was observed. Despite the fact that higher indices for two-year average yield capacity are recorded in case of light pruning, the moderate pruning is considered as the best variant, since in that case relatively higher yield capacity (49 kg and19 kg) and high index of the average fruit weight (110 $\mathrm{g}$ and $68 \mathrm{~g})$ is recorded.

\section{Conclusion}

Studing the pruning peculiarities of the plum tree in conditions of the Armavir community in the Armavir region the following conclusions were induced:

1. In case of implementing light and moderate pruning both studied varieties have recorded the maximum indices in the average leaf area: Vengerka domestica $-9.25 \mathrm{~m}^{2}$, and Fortune variety $-8.12 \mathrm{~m}^{2}$.

2. When implementing pruning of light and moderate intensity the average number of the shoots in the plum varieties of Vengerka domestica and Fortune has exceeded that of developed in case of severe pruning. When implementing severe/heavy pruning in the plum variety of Vengerka domestica 27 shoots were developed and in the Fortune variety the average number of shoots per tree was calculated as 37 .
3. Out of the three pruning types (light, moderate, severe/ heavy) the moderate pruning is considered to be the best variant, since in that case relatively higher yield capacity (49 kg and $19 \mathrm{~kg}$ ) and higher index of average fruit weight (110 $\mathrm{kg}$ and $68 \mathrm{~kg}$ ) is recorded.

Based on the aforestated conclusions it is recommended that pruning of moderate intensity should be annually implemented in the orchards of Fortune plum tree variety, while in those of Vengerka domestica variety light or moderate pruning should be annually implemented. Besides, in the plantings of both investigated varieties the light pruning should be successively substituted by the heavy or moderate pruning, as in case of annual application of light pruning, the vegetative growth of the trees will significantly decline, the annual plant growth and fruiting balance will be disrupted causing premature aging of the trees. The plum varieties of Fortune should be used for further investigations.

\section{References}

1. Cherepakhin. V.I. (1983). Pruning Fruit Trees in Intensive Orchards, - Moscow (in Russian).

2. Margaryan, A.E., Shahinyan, H.N. (1976). Horticulture. Yerevan, - $560 \mathrm{p}$.

3. Stepanyan, A.G. (2006). Drupaceous and Pomaceous Fruit Varieties, Yerevan, 21 p. (in Armenian).

4. Stepanyan, E.R. (2013). The Effect of Different Pruning Intensities on the Growth and Yield Capacity of the New Plum Tree Varieties Imported to Armenia // Agriscience and Technology 5-6. - Yerevan, - pp. 257-262. 